\title{
ON A NEW GENUS AND TWO NEW SPECIES OF PYGIDIIDAE, A FAMILY OF. SOUTH AMERICAN NEMATOGNATHS ')
}

BY

\author{
CARL H. EIGENMANN.
}

(With Plates III and IV)

In the "The Pygidiidae, a family of South American Catfishes" (Mem. Carnegie Mus. VII, Sept. 1918, pp. 259-398, plates XXXVI-LVI, 39 text figures), I described and figured ninety-seven species of the Pygidiidae. They were relegated into six subfamilies, Nematogenyinae, Pygidiinae, Pareiodontinae, Stegophilinae, Vandelliinae, and Tridentinae.

The most primitive of the genera is no doubt Nematogenys, (fig. 9) of north-central Chili. In it the maxillary is rudimentary and is continued as a barbel similar to that in the Nematognaths in general. The chin bears one pair of barbels. The opercle fig. 8 (18) and interopercle (17) are unarmed. In all the other genera mental barbels are lacking, there are normally two barbels at the end of the maxillary, and in all the known genera the opercle and interopercle are provided with spines or hooks.

Particular interest centers in the Vandelliinae, some members of which are said to be parasitic, others urinophilous, entering the urethra of bathers and the Stegophilinae, some of which attach themselves to other fishes or to man to feed on the blood of the victim.

The new genus, Apomatoceras, evidently belongs to the parasitic group of Stegophilinae. The new species, Urinophilus erythrurus belongs to the group of Vandelliinae to which belong the "Caneras" or "Candirus" said to enter the urethra of incautious bathers.

The specimens described were all collected by Dr. William Ray Allen during the Centennial Expedition ${ }^{2}$ ) of Indiana University, which crossed South America from Callao, Peru to Para, Brazil.

\section{APOMATOCEROS gen. nov.}

A genus of the Stegophilinae, most nearly related to Acanthopoma, from which it differs in the absence of spines on the opercle, the forked caudal, the spreading upper jaw, short lower jaw and in the union of the gill membranes with the isthmus, except for a broad, free membrane.

\section{APOMATOCEROS ALLENI sp. nov.}

15500, I., Type, $146 \mathrm{~mm}$. Rio Morona, caught with a seine on a sand bar. Oct. 1920 .

Head 8 ; depth 9 ; depth of head 16 ; eye 5.33 in the length of the head, interocular equals

1) Contribution from the Zoological Laboratory of Indiana University, Number 190

2) "The Centennial Expedition of Indiana University to Peru." Science. N. S. LIII. 1921, pp. 377-379; Indian a University Alumni Quarterly, VIII, 1921. pp. 111 to 140. 
snout and half eye; pectoral 11 in the length; upper caudal lobe equal to the length of the head; lower a little longer. Depth of caudal peduncle 2.4 in its length; D. 9; A. 8, base of anal nearly twice as long as base of dorsal. Compressed behind the pectorals, greatly depressed in front, the pectorals nearly horizontal.

Mouth very large, subcircular, the upper jaw flexible, curling inward, prolonged backward to near the tips of the interopercular spines; terminal barbel of the maxillary reaching tips of the interopercular spines, the lower barbel very small, scale-like in shape; the lower jaw firm, not reaching forward to middle of eye. The upper jaw can evidently be expanded into a disk for attachment; seven very regularly arranged, concentric rows of teeth in the upper jaw; shorter rows interpolated between these near the symphysis to a total of eleven, the number of rows decreasing to four at the end of the pre-maxillary, only the outer four rows continued across the middle, the others interrupted in the middle by a naked area.

Four rows of similar teeth in the lower jaw; those of the two rami separated by a considerable space free from teeth. Gill membranes united and joined to the isthmus, but with a wide free membrane across the isthmus. Distance between anterior nares more than twice the distance between the posterior. A dermal median keel from base of the last ventral ray to between the tips of the pectorals.

Interopercle with a series of five straight spines fig. 9 (17). No opercular spines fig. 9 (18).

A black spot on the nape, a narrow black band across the base of the caudal, a broad silvery lateral band, otherwise translucent.

The alimentary canal is a thin-walled tube, containing many fish scales toward the end.

\section{URINOPHILUS ERYTHRURUS sp. nov.}

15713, I., 3, 49-53 mm. Rio Morona, Gosulima Cocha.

15717, I., 1, $127 \mathrm{~mm}$. R. Ucayale, near Orellana.

15715, I., 3, 64-74 mm. R. Paranapura, Yurimaguas.

15584, I. Types and paratypes, 10, 120-145 mm. Rio Morona. Dr. W. R. Allen.

15714, I., 1, 43 mm. Rio Morona? Dr. W. R. Allen.

Head 10.5-11; depth 10 ; D. 9-11; A. 7-9.

Body compressed; head depressed, flat below, arched above, depth of head equals distance between centers of eye; distance between eyes equal to snout; eye about 5 in the head; 5 to 9 teeth in a crescent (on the premaxillary?) below the snout; a series of about four, claw-like teeth on the maxillaries, the teeth concealed in a fleshy pocket fig. $10(12)$, fig. 14; very few recurved teeth at the ends of the mandible fig. 11 and $12(20)$, the tips of the mandible widely separated; outer barbel extending to the end of the interopercular spines; interopercular spines numerous (about ten) their tips curved fig. 10(17); opercular spines more numerous, about twenty-five, curved at the tip (18; pectorals about equal to the head less half the snout, distance between origin of ventrals and base of caudal about equal to a third of the length, origin of dorsal forward of the vertical from the origin of the anal; depth of caudal peduncle three or more in its length; caudal emarginate.

Plumbeous above, white below, the middle of the caudal dark, the outer parts pink in life.

The maxillary is a two parted bone, the inner (mesial) part articulates in a movable joint with the wings of the ethmoid and is free of teeth, the distal part carries several overlapping, claw-like teeth in a single series. The barbels are continous from the end of the maxillary.

A thin blade-like bone covers the end of the maxillary protecting the teeth; the inner, proximal end of this blade-like bone is narrowed and curved around the maxillary (fig. $10(12 a)$. 


\section{EXPLANATION OF FIGURES}

\section{EXPLANATION OF NOTATIONS}

1, Premaxillary; 2, ethmoid; 3, lateral ethmoid; 4, nasal; 5. frontal; 6, sphenotic; 7. pterotic; 8, supra-occipital; $8 a$, basi-occipital; 9 , epiotic; 10 , supraclavicle; 11 , parapophysis of coalesced vertebrae; 12 , maxillary; $12 a$, supplemental; 13 , palatine; 14 , metapterygoid; 15 , quadrate; 16 , pre-opercle; 17 , interopercle; 18 , opercle; 19 , hyomandibular; 20, mandible; 21 , parasphenoid; 22, prootic; 23 , alisphenoid.

Fig. 1. Apomatoceros alleni Eigenmann. Type.

Figs. 2, 3, and 4. The same from above, from below with the lips closed and partly expanded.

Fig. 5. Skull of Urinophilus erythrurus from above.

Fig. 6. The same from below.

Fig. 7. The same from the side.

Fig. 8. Suspensorium of Nematogenys inermis.

Fig. 9. Suspensorium of Apomatoceros.

Fig. 10. Suspensorium of Urinophilus erythrurus.

Fig. 11. Mandible of the same from the side.

Fig. 12. The same from above.

Fig. 14. Outlines of individual teeth from the maxillary of the same.

Figs. 13, 15, \& 16. Urinophilus erythrurus. Type. 
BijdRAGEN tOT DE DiERKUnde. - Carl H. Eigenmann.

PI. III.
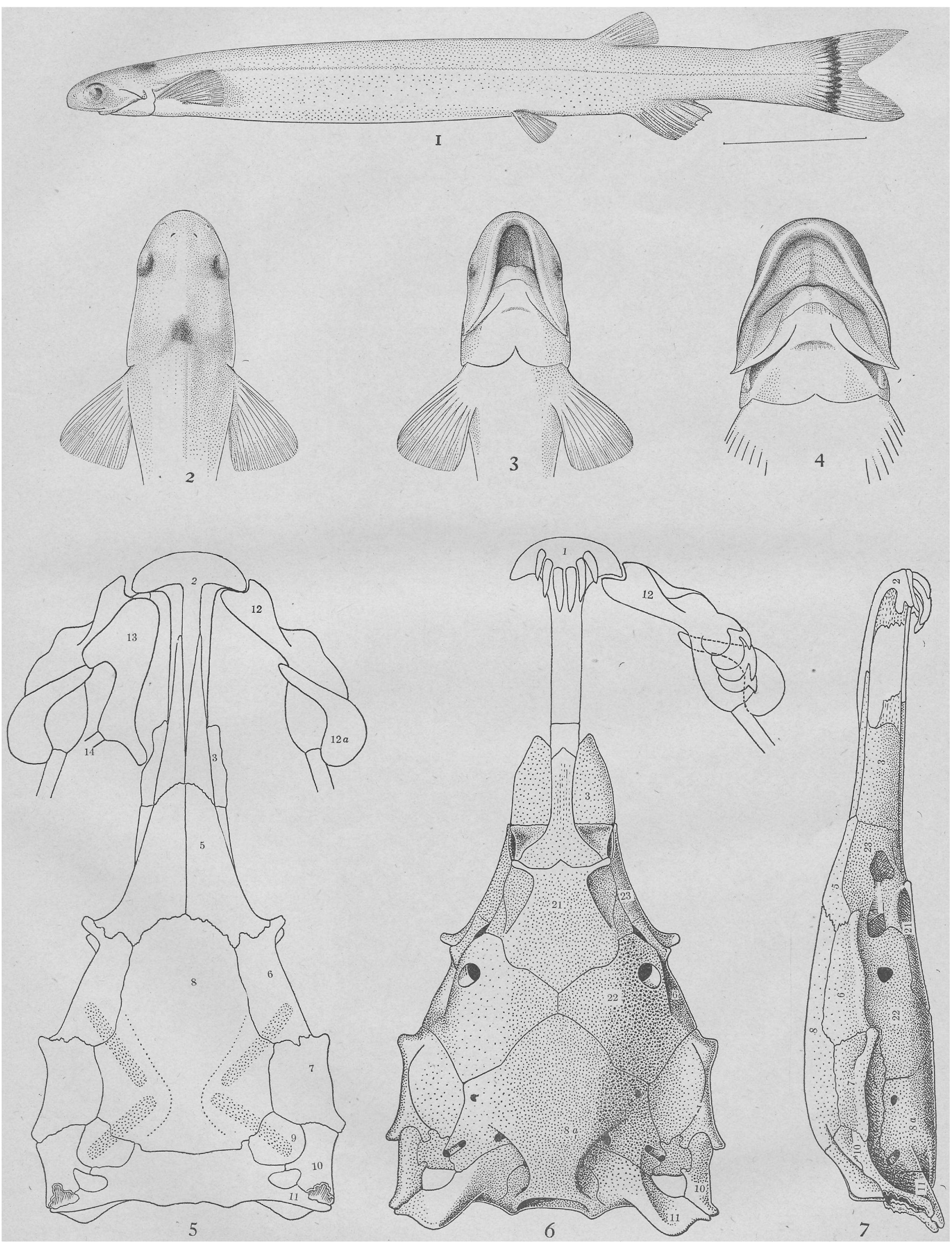

Downloaded from Brill.com๑4/26/2023 01:40:14PM

via free access 


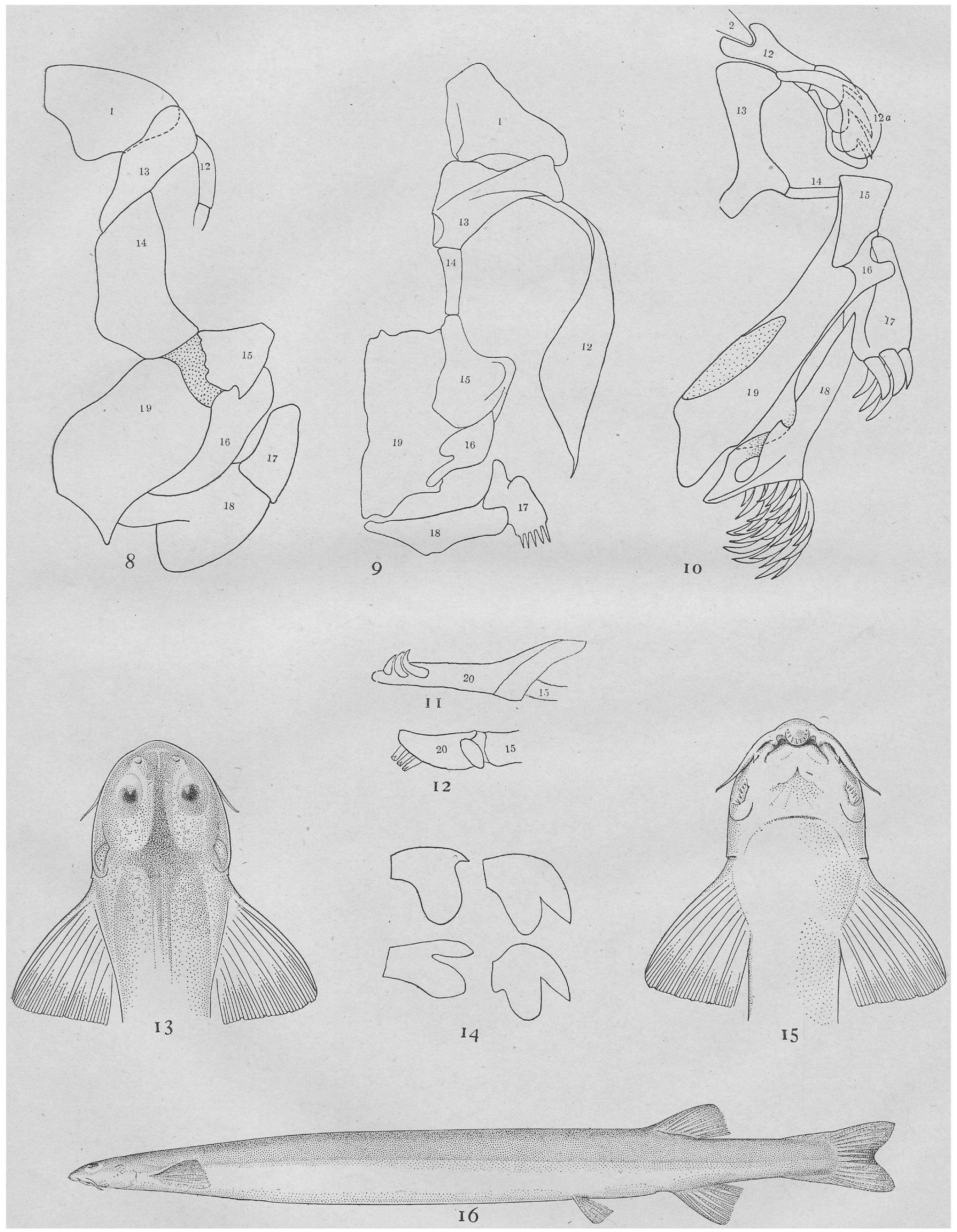

